\title{
Widening the gap between measurement and modelling of secondary organic aerosol properties?
}

\author{
N. Good ${ }^{1, *}$, D. O. Topping ${ }^{1,2}$, J. Duplissy ${ }^{3, * *}$, M. Gysel $^{3}$, N. K. Meyer ${ }^{4, * * *}$, A. Metzger $^{3}$, S. F. Turner ${ }^{1, * * * *}$, \\ U. Baltensperger ${ }^{3}$, Z. Ristovski ${ }^{4}$, E. Weingartner ${ }^{3}$, H. Coe ${ }^{1}$, and G. McFiggans ${ }^{1}$ \\ ${ }^{1}$ School of Earth Atmospheric and Environmental Sciences, University of Manchester, Manchester, M13 9PL, UK \\ ${ }^{2}$ National Centre for Atmospheric Sciences, University of Manchester, Manchester, M13 9PL, UK \\ ${ }^{3}$ Laboratory of Atmospheric Chemistry, Paul Scherrer Institut, 5232 Villigen, Switzerland \\ ${ }^{4}$ ILAQH, Queensland University of Technology, P.O. Box 4233, Brisbane QLD, 4001, Australia \\ * now at: Laboratoire de Météorologie Physique, Blaise Pascal Univ., 63000, Clermont Ferrand, France \\ *** now at: Department of Physics, Centre Européen de la Recherche Nucléaire, 1211 Geneva, Switzerland \\ **** now at: Laboratory for Energy Systems Analysis, Paul Scherrer Institut, 5232 Villigen, Switzerland \\ ${ }^{* * * * *}$ now at: Experimental Solid State Physics Group, Blackett Laboratory, Imperial College London, SW7 2BW, UK
}

Received: 4 September 2009 - Published in Atmos. Chem. Phys. Discuss.: 26 October 2009

Revised: 24 February 2010 - Accepted: 2 March 2010 - Published: 15 March 2010

\begin{abstract}
The link between measured sub-saturated hygroscopicity and cloud activation potential of secondary organic aerosol particles produced by the chamber photo-oxidation of $\alpha$-pinene in the presence or absence of ammonium sulphate seed aerosol was investigated using two models of varying complexity. A simple single hygroscopicity parameter model and a more complex model (incorporating surface effects) were used to assess the detail required to predict the cloud condensation nucleus (CCN) activity from the subsaturated water uptake. Sub-saturated water uptake measured by three hygroscopicity tandem differential mobility analyser (HTDMA) instruments was used to determine the water activity for use in the models. The predicted $\mathrm{CCN}$ activity was compared to the measured $\mathrm{CCN}$ activation potential using a continuous flow $\mathrm{CCN}$ counter.

Reconciliation using the more complex model formulation with measured cloud activation could be achieved widely different assumed surface tension behavior of the growing droplet; this was entirely determined by the instrument used as the source of water activity data. This unreliable derivation of the water activity as a function of solute concentration from sub-saturated hygroscopicity data indicates a limitation in the use of such data in predicting cloud condensation nucleus behavior of particles with a significant organic fraction. Similarly, the ability of the simpler single parameter model to
\end{abstract}

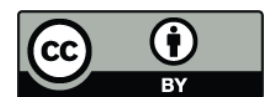

Correspondence to: G. McFiggans (g.mcfiggans@manchester.ac.uk) predict cloud activation behaviour was dependent on the instrument used to measure sub-saturated hygroscopicity and the relative humidity used to provide the model input. However, agreement was observed for inorganic salt solution particles, which were measured by all instruments in agreement with theory.

The difference in HTDMA data from validated and extensively used instruments means that it cannot be stated with certainty the detail required to predict the $\mathrm{CCN}$ activity from sub-saturated hygroscopicity. In order to narrow the gap between measurements of hygroscopic growth and CCN activity the processes involved must be understood and the instrumentation extensively quality assured. It is impossible to say from the results presented here due to the differences in HTDMA data whether: i) Surface tension suppression occurs ii) Bulk to surface partitioning is important iii) The water activity coefficient changes significantly as a function of the solute concentration.

\section{Introduction}

Aerosol in the atmosphere comprises numerous and diverse components originating from both natural and anthropogenic activities. In addition to the already well-established presence of the major inorganic components, studies over the last few decades have identified that a significant fraction of aerosol is composed of organic material in a variety of

Published by Copernicus Publications on behalf of the European Geosciences Union. 
locations across the world e.g. (Andreae et al., 1988; Middlebrook et al., 1998; Zhang et al., 2007; Heald et al., 2008). A large proportion of this can be secondary; that is, formed or transformed in the atmosphere (Kanakidou et al., 2005; Hallquist et al., 2009), in large part by interaction with gaseous components. The composition of secondary organic aerosol (SOA) in the atmosphere is complex and this may be expected to propagate into the properties and behavior. However, since it may comprise a large fraction of the ambient aerosol, SOA will significantly contribute to the aerosol direct and indirect effects on climate and weather (Haywood and Boucher, 2000; Forster et al., 2007). Quantification of SOA formation, transformation and properties is important in adequately accounting for its effects. Most specifically, it is necessary to quantify the optical properties, hygroscopicity and cloud droplet activation behavior of SOA and how they relate to each other. The relationship between these last two properties is the focus of this work.

The reactions leading to SOA formation are complex and may proceed via multiple pathways, forming numerous oxygenation products from each of many potential parent volatile organic compounds (VOCs) such as $\alpha$-pinene (Jenkin, 2004). Photochemical reaction chamber studies have been used to explore specific atmospheric processes with reduced complexity (Baltensperger et al., 2005; Carter et al., 2005). With respect to aerosol processes, it has been shown that it is necessary to work at conditions and concentrations approaching those found in the atmosphere to more closely replicate particle composition and behavior: The effects of VOC to $\mathrm{NO}_{\mathrm{x}}$ ratio (Presto et al., 2005b), water vapour concentration (Seinfeld et al., 2001) and photochemical aging (Presto et al., 2005a) have all been shown to affect SOA formation. Duplissy et al. (2008) showed that decreasing the initial VOC concentration towards atmospheric levels altered the aerosol composition and the hygroscopic properties. It is not entirely clear which aspects of atmospheric processes must be studied under conditions of increased complexity to enable extrapolation of experimental results to provide atmospherically relevant representations. In order to simulate atmospheric processes it is important that those dominating behavior in the artificial environment are the same as those in the atmosphere. This has hitherto been attempted by creating conditions in the chamber with atmospherically realistic ratios and concentrations of the major oxidising agents and precursors.

Describing the aerosol water uptake in the warm moist atmosphere (both cloud-free and in-cloud) requires an adequate description of the equilibrium behavior of a liquid solution droplet with respect to the water content of its environment. In bulk solution Raoult's law describes the relevant thermodynamic quantity, the water activity $\left(a_{w}\right)$. The influence of curvature relevant to activation of sub-micron aerosol particles is captured in the Kelvin term (incorporating the effect of surface tension on equilibrium droplet size). These are combined in the primitive form of the Köhler equation
(Köhler, 1936; McFiggans et al., 2006), relating the equilibrium droplet size to the saturation ratio of water (or the relative humidity):

$S=\frac{\mathrm{RH}}{100}=a_{w} \exp 0.75 \mathrm{~mm} \quad K_{e}=a_{w} \exp \left(\frac{4 v_{w} \sigma_{\mathrm{sol}}}{\mathrm{RTD}}\right)$

where $S$ is the saturation ratio, $\mathrm{RH}$ is the relative humidity, $a_{w}$ is the water activity, $K_{e}$ is the Kelvin factor, $v_{w}$ is the partial molar volume of water, $\sigma_{\text {sol }}$ is the surface tension of the solution at the droplet composition, $R$ is the universal gas constant, $T$ is the droplet temperature and $D$ is the particle diameter.

It is extremely difficult to directly measure all the individual variables in Eq. (1), and a general analytical solution to the relationship is generally not accessible or practical. Simplification of the Köhler equation is therefore required to relate sub- and supersaturated aerosol behavior. Simplification is achieved in different model solutions by treating varying amounts of the thermodynamics and applying empirical parameterisations. The primitive Köhler equation can be simplified for example by assuming ideal behavior, solubility is often considered assuming fractions of the particle are either insoluble or fully soluble and surface tension is sometimes assumed to be that of pure water. All these assumptions and more are reviewed in (McFiggans et al., 2006).

The sub- and supersaturated properties may be described solely by the quantities included in, and the relationship defined by the Köhler equation (Eq. 1). Measurements of these properties should therefore be consistent with predictions made with a suitably accurate and precise form of the relationship. This manuscript is concerned with testing the consistency of such measurements with predictions made using two different levels of simplification of the Köhler equation. Focusing on the simplest form of the expression, a working hypothesis may be framed as follows: supersaturated behavior can be accurately predicted from measured sub-saturated behavior using a single parameter to represent hygroscopicity in the Köhler equation, assuming the surface tension is always that of water. The study described in this paper uses measurements of sub- and supersaturated hygroscopicity during chamber photo-oxidation experiments to address this hypothesis.

Photo-oxidation experiments were performed in the presence and absence of an inorganic seed. Two models were used to parameterise the sub-saturated water uptake of the aerosol formed and predict their potential cloud condensation nuclei (CCN) activity, the Aerosol Diameter Dependent Equilibrium Model (ADDEM) (Topping et al., 2005a,b) and the "Kappa Köhler Model" ( $\kappa$-model) (Petters and Kreidenweis, 2007). ADDEM is used to investigate the effect of surface tension, molecular weight, density and bulk-surface partitioning whilst deriving the $a_{w}$ from hygroscopicity tandem differential mobility analyser (HTDMA) measurements. The $\kappa$-model has the advantage of being relatively simple; it will 
Table 1. Overview of the design features of each HTDMA. DMA 2 sheath type (Sheath), DMA 2 operating temperature ( $\left.T_{\text {DMA2 }}\right)$, residence time in aerosol humidifier $\left(\tau_{\text {humid }}\right)$ and the humidifier type (Humid.Type).

\begin{tabular}{lrrrr}
\hline HTDMA & Sheath & $\mathrm{T}_{\text {DMA2 }}$ & $\tau_{\text {humid }}$ & Humid.Type \\
\hline $\mathrm{H}_{\text {MAN }}$ & closed loop & $\sim 25-29^{\circ} \mathrm{C}$ & $30 \mathrm{~s}$ & Gore-Tex \\
$\mathrm{H}_{\text {PSI }}$ & closed loop & $20^{\circ} \mathrm{C}$ & $15 \mathrm{~s}$ & Gore-Tex \\
$\mathrm{H}_{\mathrm{QUT}}$ & closed loop & $\sim 25-29^{\circ} \mathrm{C}$ & $5 \mathrm{~s}$ & Nafion \\
\hline
\end{tabular}

be used with the mean hygroscopic growth factors at a single RH from the HTDMAs as the input, to predict the CCN activity. The model predictions will then be compared to the measured $\mathrm{CCN}$ activity.

\section{Methods}

\subsection{Experimental design}

The experiments in this study were performed at the Paul Scherrer Institute (PSI) smog chamber (Paulsen et al., 2005). Briefly, the chamber comprises a $27 \mathrm{~m}^{3}$ Teflon bag which can be illuminated by 4 xenon arc lamps; a purified air system supplies the chamber with particle free air, $\mathrm{CO}_{2}$ and $\mathrm{O}_{2}$ are controlled to typical atmospheric levels and other trace gases are scrubbed out to sub ppb levels. A mass flow system allows the controlled addition of $\mathrm{NO}_{\mathrm{x}}, \mathrm{O}_{3}$ and water vapour to the chamber as required.

Experiments were conducted to investigate the hygroscopic properties of aerosol produced from the photooxidation of $\alpha$-pinene. The experiments were initiated by injecting a nominal concentration of the precursor into the conditioned chamber, as described in Table 2. Oxidation of the precursor was then initiated by illuminating the chamber. Additionally for seeded experiments a background concentration of ammonium sulphate aerosol was injected prior to illumination. The seed aerosol was generated using an electrospray generator (TSI, model 3484), filling the chamber with a uniform concentration of nearly monodisperse aerosol (mean diameter $33 \mathrm{~nm}$, geometric standard deviation of 1.3) within $1 \mathrm{~h}$ (for more details see Meyer et al., 2009). The mobility number size distribution was measured for the duration of each experiment using a scanning mobility particle sizer (SMPS) comprising a differential mobility analyser (DMA, TSI 3071) and a condensation particle counter (CPC, TSI, 3022).

\subsection{Measurements: unseeded experiments}

The sub-saturated water uptake of the unseeded SOA was measured using 3 different HTDMA instruments $\left(\mathrm{H}_{\text {MAN }}\right.$, $\mathrm{H}_{\mathrm{QUT}}$ and $\mathrm{H}_{\mathrm{PSI}}$ ) (Cubison et al., 2005; Johnson et al., 2008; Duplissy et al., 2009). The HTDMAs were used to determine the mean hygroscopic growth factor $\left(\mathrm{GF}_{\mathrm{D} 0, \mathrm{RH}}\right)$ for particles of a selected dry size $\left(D_{0}\right)$ and at a set RH using the inversion,
Table 2. Experimental conditions; proton-transfer mass spectrometer measured precursor concentration (conc.), duration, precursor (VOC) to $\mathrm{NO}_{\mathrm{x}}$ ratio, type (seeded or unseeded) and the date (during August 2006) for reference with Duplissy et al. (2009) and Meyer et al. (2009). For all experiments the chamber was conditioned to $20{ }^{\circ} \mathrm{C}$ and $50 \% \mathrm{RH}$.

\begin{tabular}{lrrrr}
\hline Conc. & Duration & VOC $: \mathrm{NO}_{\mathrm{x}}$ & Type & Date \\
\hline $8.9 \mathrm{ppb}$ & $12 \mathrm{~h}$ & $1: 1$ & Unseeded & $8 \mathrm{th}$ \\
$37.0 \mathrm{ppb}$ & $25 \mathrm{~h}$ & $1: 2$ & Unseeded & $11 \mathrm{th}$ \\
$10.3 \mathrm{ppb}$ & $8 \mathrm{~h}$ & $2: 1$ & Seeded & $17 \mathrm{th}$ \\
$9.95 \mathrm{ppb}$ & $7 \mathrm{~h}$ & $2: 1$ & Seeded & $22 \mathrm{nd}$ \\
$10.62 \mathrm{ppb}$ & $23 \mathrm{~h}$ & $2: 1$ & Seeded & $28 \mathrm{th}$ \\
\hline
\end{tabular}

analysis and quality assurance procedures of Gysel et al. (2009). The raw data is checked on a scan by scan basis to ensure there are no anomalies in the recorded counts, temperatures, pressures, flows and RHs. Scans with less than 50 total counts are disregarded. When running at a constant $\mathrm{RH}$ any scans where the average $\mathrm{RH}$ is outside $\pm 1.5 \%$ of the set point are disregarded. The HTDMAs ran humidograms where the RH was systematically stepped over a range of $\sim 50 \%$ to $>91 \%$ to determine GF as a function of RH.

Although the principle of operation for each of the HTDMAs is the same, there are certain design features unique to each. Table 1 highlights the principle unique design and operational details of each HTDMA. A more detailed description of each HTDMA is given in the supplementary material (http://www.atmos-chem-phys.net/10/ 2577/2010/acp-10-2577-2010-supplement.pdf) which accompanies this manuscript and in Duplissy et al. (2009). All 3 HTDMAs operate closed loop DMA sheaths, which should help maintain the same equilibrium between the gas and aerosol phases as inside the photo-oxidation chamber. HPSI is built into the structure surrounding the chamber. $\mathrm{H}_{\text {MAN }}$ and $\mathrm{H}_{\mathrm{QUT}}$ were located on a different sampling line outside the chamber, resulting in longer sample residence time from the chamber to the instrument inlet. The residence time of the humidified aerosol prior to entering DMA2 $\left(\tau_{\text {humid }}\right)$ is different for each system. The possible consequences of these differences on the measured data are discussed in Sect. 3.1. The temperature in $\mathrm{H}_{\mathrm{PSI}}$ is controlled within an air-conditioned cabinet. $\mathrm{H}_{\mathrm{MAN}}$ and $\mathrm{H}_{\mathrm{QUT}}$ insulate the humidified DMA to ensure the temperature is stable. $\mathrm{H}_{\text {MAN }}$ and $\mathrm{H}_{\mathrm{PSI}}$ use a GoreTex ${ }^{\circledR}$ membrane to condition the sample aerosol. $\mathrm{H}_{\mathrm{QUT}}$ uses Nafion ${ }^{\circledR}$ membranes to control the RH.

The potential of the aerosol to act as $\mathrm{CCN}$ was measured by the DMT continuous flow CCN counter (Roberts and Nenes, 2005). The CCN counter was operated in two different modes; polydisperse and monodisperse. In the monodisperse mode the aerosol was size selected using a DMA before being sampled by the CCN counter, operated in parallel to a CPC (TSI 3025) in order to determine the fraction of particles that have been activated $\left(F_{A}\right)$ at a set supersaturation as a 
function of diameter. In polydisperse mode the $\mathrm{CCN}$ counter sampled directly from the chamber. The $\mathrm{CCN}$ counter sampled from the same line as $\mathrm{H}_{\mathrm{MAN}}$ and $\mathrm{H}_{\mathrm{QUT}}$ with a residence time of $\sim 20$ s between the chamber and their inlets.

During the unseeded $\alpha$-pinene experiments the $\mathrm{CCN}$ counter was run in polydisperse mode. The mode of the size distribution increases rapidly during the unseeded experiments, making it difficult to constrain the activation behavior by sampling a single diameter. By sampling the polydisperse aerosol at a number of set point supersaturations exhibiting a range of activation behavior the $S_{c}$ can be determined as a function of dry diameter $\left(D_{0}\right)$ when convolved with the size distribution assuming that the aerosol is internally mixed and that the larger aerosol particles are always more $\mathrm{CCN}$ active. These assumptions are backed up by previous unseeded $\alpha$-pinene SOA studies in the PSI chamber where HTDMA measurements showed an internally mixed aerosol and that the size dependence of the hygroscopic growth factor at any one time was not large and likely attributable to the Kelvin effect alone (Duplissy et al., 2008).

\subsection{Measurements: seeded experiments}

During the seeded experiments the $\mathrm{CCN}$ counter was run in monodisperse mode. By selecting dry diameters above the mode of the number size distribution (thus minimising the number of multiply charged particles sampled) the effect of the newly formed SOA on the activation behavior could be measured. The seeded experiments are better suited to the monodisperse sampling mode because the presence of the seed results in a relatively slow increase in the mode of the number size distribution throughout the experiment. Therefore over a $\sim 20$ min CCN measurement cycle the mode of the distribution will remain below the size selected. Also, as the critical supersaturation of the seed is known a-priori, the initial supersaturations to be set by the $\mathrm{CCN}$ counter are known and the $S_{c}$ can be tracked throughout the experiment without downtime searching for the correct settings. The supersaturation set point was increased in a series of 5 steps over $\sim 20$ min periods to build up an activation spectrum.

The SMPS was used to measure the aerosol number size distribution. The initial near mono-disperse seed aerosol then allowed the proportion of ammonium sulphate seed and SOA for particular diameter particle in the chamber to be estimated by analysis of the number size distribution, as the seeded experiments progressed. The volume fraction of the SOA in a particle of a given dry size at a certain time was determined from the evolution of the particle number size distribution measured by the SMPS. The calculation of the SOA fraction is described explicitly in Meyer et al. (2009). By assuming that the percentile values of seed diameter are equal throughout the experiment and ignoring coagulation the error is approximately $5 \%$.

\subsection{Quantitative validation of the instrumentation using nebulised ammonium sulphate}

Validation of the performance of all the instruments was carried out by sampling pure ammonium sulphate particles. A solution of ammonium sulphate (Fluka, $>99.5 \%$ ) was nebulised (TSI, 3076) and dried to below $10 \%$ RH by passing the aerosol through a desiccant. The flow stream was sampled by the $\mathrm{CCN}$ counter and each of the 3 HTDMA instruments.

Prior to entering the $\mathrm{CCN}$ counter the ammonium sulphate aerosol was size selected using a DMA (TSI, 3071). Six sizes between $30 \mathrm{~nm}$ and $130 \mathrm{~nm}$ were selected in turn. By adjusting the temperature gradient down the column (i.e. the set point supersaturation), the activated fraction (the number of CCN divided by the total number of particles of the size selected at a supersaturation) was measured as it increased from 0 to 1 . An accurate calibration of the $\mathrm{CCN}$ counter was obtained by assuming that the temperature gradient at which $50 \%$ of the singly charged particles are counted as $\mathrm{CCN}$ corresponds to the $S_{c}$ calculated for the size selected aerosol using ADDEM (Topping et al., 2005a) thus providing an accurate calibration of the temperature gradient set in the CCN counter. For a perfectly monodisperse and internally mixed aerosol the transition into an activated cloud droplet should occur abruptly over an infinitesimal increase in supersaturation (i.e. $0 \%$ of the aerosol should be activated or $100 \%$ ). What actually is observed is a continuous increase in activated fraction over finite changes in supersaturation, so the assumption made is that this was caused by the finite width of the DMA transfer function which was assumed to be symmetrical and therefore did not bias the results. Aerosol particles with diameters between $30 \mathrm{~nm}$ and $130 \mathrm{~nm}$ were chosen for calibration because they activate across the operational range of supersaturations in the CCN counter $(\sim 0.1$ to $1.0 \%$ ). Figure 1 (left panel) shows the measured $S_{c}$ at the set point supersaturations compared to the theoretical values (ADDEM).

The 3 HTDMA instruments sampled the nebulised ammonium sulphate aerosol, selecting dry diameters of $150 \mathrm{~nm}$ $\left(\mathrm{H}_{\mathrm{MAN}}\right), 105 \mathrm{~nm}\left(\mathrm{H}_{\mathrm{QUT}}\right)$ and $100 \mathrm{~nm}\left(\mathrm{H}_{\mathrm{PSI}}\right)$. Diameters above $100 \mathrm{~nm}$ were selected as the Kelvin effect is relatively unimportant $(<1 \%)$ at these sizes and therefore does not introduce uncertainty in comparing results to model predictions. In addition, systematic instrument errors due to small errors in the size selection of the sample are minimised. A humidogram was obtained with each HTDMA by increasing the $\mathrm{RH}$ from the minimum set point $(\sim 10 \%)$ to the maximum ( $>90 \%$ depending on the individual instrument). H $\mathrm{H}_{\text {MAN }}$ 's maximum $\mathrm{RH}$ was $\sim 92 \%$, whilst $\mathrm{H}_{\mathrm{PSI}}$ 's and $\mathrm{H}_{\mathrm{QUT}}$ 's are $\sim 95 \%$ (Duplissy et al., 2009; Johnson et al., 2008). Figure 1 (right panel) shows 3 typical humidograms where HTDMAs are measuring across the same RH range. Further humidogram data for the 3 instruments is shown in Duplissy et al. (2009). Repeated ammonium sulphate humidograms performed at various times during the campaign gives results 


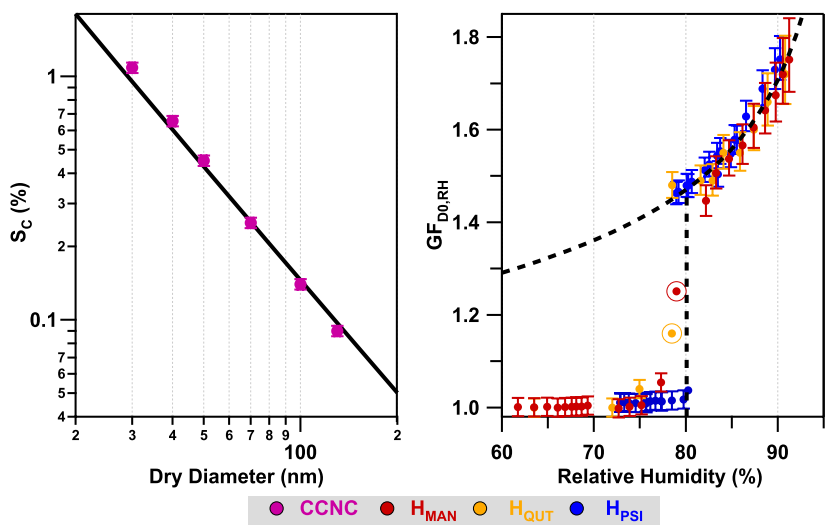

Fig. 1. Nebulised aerosol measurements. Left hand side: measured (purple circles) and theoretical critical supersaturations (black line) for ammonium sulphate. Right hand side: humidogram measurements for ammonium sulphate from the 3 HTDMAs (coloured symbols) plotted against theory (dashed black line). The circled points indicate transient data points observed close to the deliquesence point.

consistent with those in Fig. 1. The error bars on Fig. 1 (right panel) show the uncertainty in the measured growth factor due to the accuracy of the RH measurement in DMA2 and the precision of the tandem-DMA. The accuracy of the RH measurement is $1.5 \%$ for $\mathrm{H}_{\mathrm{MAN} / \mathrm{QUT}}$ and $1 \%$ for $\mathrm{H}_{\mathrm{PSI}}$. The dry diameter dependence of the theoretical growth factors values falls within the thickness of the black line on Fig. 1 and therefore we can directly compare the 3 instruments values to it and with each other.

It can be seen from Fig. 1 (right panel) that all 3 instruments measured the hygroscopic growth factor in agreement with ADDEM consistent with the estimated uncertainty. For example the data points closest to $90 \%$ give differences of 0.4, 0.2 and $0.7 \%$ between the modelled and set RH for the measured growth factor for each $\mathrm{H}_{\mathrm{MAN} / \mathrm{PSI} / \mathrm{QUT}}$ respectively. These differences are within the $1-1.5 \%$ accuracy of the respective dew point mirror. There was some deviation from theory at the deliquescence point (theoretically $79.9 \%$ for $D_{0}=150 \mathrm{~nm}$ ) seen by $\mathrm{H}_{\text {MAN }}$. The reasons for observed nonprompt deliquescence in HTDMA instruments have been investigated previously (Biskos et al., 2006; Duplissy et al., 2009) and was likely due in this instance to the aerosol RH in the second DMA not being constant over the measurement interval due to small changes in RH of HMAN's sample aerosol at the inlet to the second DMA which is used to control the RH of the second DMA. The performance of the HTDMA instruments is discussed in more detail later.

\subsection{Model descriptions}

\subsubsection{ADDEM}

The Aerosol Diameter Dependent Equilibrium Model (ADDEM) has previously been used to predict aerosol subsaturated water uptake or the $S_{c}$ of an aerosol particle given the molecular identity and mole fractions of its constituents and the particle size (Topping et al., 2005a,b, 2007). In this mode of operation, ADDEM directly solves the primitive form of the Köhler equation (Eq. 1), evaluating the $a_{w}$ using a combination of a mole fraction scale ionic interaction model for inorganic components and a group contribution method for organic components, as detailed in the citations above. In this current work, estimates for the $a_{w}$ relationships in ADDEM were obtained directly by combining the HTDMA humidogram measurements with a range of estimates for the effective molar mass and pure component density assuming a single aqueous solute. The molar mass values $(200,300,400$ and $\left.500 \mathrm{~g} \mathrm{~mol}^{-1}\right)$ and densities $(1200,1400,1300,1600$ and $1800 \mathrm{~kg} \mathrm{~m}^{-3}$ ) were used to derive water activities and were selected to provide a sensitivity across the possible range in the real atmosphere. For the $\alpha$-pinene derived SOA produced in the PSI chamber the density is $\sim 1300 \mathrm{~kg} \mathrm{~m}^{-3}$ (Alfarra et al., 2006). The densities and molar masses were used within Eqs. (14-16) of Kreidenweis et al. (2005) to derive expressions where the Van't Hoff factor varies as a function of concentration and is incorporated within ADDEM. Thus this approach uses the $\mathrm{GF}_{\mathrm{D} 0, \mathrm{RH}}$ at all RHs to generate the $a_{w}$ behavior as a function of component mole fraction to avoid use of one point to represent hygroscopicity across the full $\mathrm{RH}$ range. The $a_{w}$ is calculated from $\mathrm{GF}_{\mathrm{D} 0, \mathrm{RH}}$ by assuming the surface tension is that of water in the Kelvin term. This will only introduce a small error $(<<1 \%)$ if the surface tension is not that of water as the Kelvin term is always close to 1 at the RHs in the HTDMAs. Since the HTDMA instruments have a maximum controllable $\mathrm{RH}$, data are unavailable approaching the point of activation. Therefore in order to parameterise the water content beyond the maximum RH (91\% to $95 \%$ depending on the HTDMA) it was necessary to extrapolate the measured humidogram. The full shape of the growth factor curve (humidogram) has been used to extrapolate toward the very dilute solution at the point of activation using cubic spline interpolation, using the fact that the mole fraction of water is 1 when $a_{w}$ is 1 as the end point. Predictions from ADDEM directly used these relationships to predict the critical point. Combinations of all the physical properties (molar mass and density) were employed to provide a range of fitted $a_{w}$. In addition, each $a_{w}$ fit was used with the surface tension of pure water and with surface tension varying as a function of solute concentration using a parameterisation based on Suwanee River fulvic acid (Topping et al., 2007). Finally, a version of ADDEM incorporating bulk to surface partitioning using a Suwanee River fulvic acid surface tension parameterisation was used (Topping et al., 2007). By including this 
effect we need to account for how material distributes itself between the bulk and surface layer, thus influencing concentrations in the Raoult and Kelvin terms. Importantly, calculating this distribution of material between a bulk and surface layer relies on knowledge of the surface tension profile, or the relation between surface tension and concentration. Unfortunately such data are only available for a limited number of compounds and therefore a proxy was used in this study. Detailed equations for partitioning calculations can be found in (Topping et al., 2007).

\subsection{2 $\kappa$-model}

The $\kappa$-model (Petters and Kreidenweis, 2007) employs a simplified form of the primitive Köhler equation (Eq. 1), whereby the saturation ratio (S) between the droplet and air interface can be represented in terms of just its dry diameter, a constant surface tension and a hygroscopicity parameter $(\kappa)$. Once a value for $\kappa$ has been calculated the water uptake across all saturation conditions can be determined. The $\kappa$ value defines the relationship between $a_{w}$ and the volume of solute $\left(V_{s}\right)$ and solvent $\left(V_{w}\right)$ as shown in Eq. (3). Equation (3) is then defined in terms of the particle's growth factor $\left(\mathrm{GF}_{\mathrm{D} 0, \mathrm{RH}}\right)$. To calculate the Kelvin term $\left(K_{e}\right)$ the assumption that the surface tension $(\sigma)$ is that of water $\left(\sigma=\sigma_{w}\right)$ which is widely used in conjunction with the $\kappa$ parameter is applied. Combined with the expression for $a_{w}$, this yields the simplified $\kappa$-Köhler Eq. (3).

$$
\begin{aligned}
& \frac{1}{a_{w}}=1-\kappa \frac{V_{s}}{V_{w}} \\
& S \approx \frac{\mathrm{GF}_{\mathrm{D} 0, \mathrm{RH}}^{3}-1}{\mathrm{GF}_{\mathrm{D} 0, \mathrm{RH}}^{3}-(1-\kappa)} \exp \left(\frac{4 v_{w} \sigma_{w}}{\mathrm{RTGF}_{\mathrm{D} 0, \mathrm{RH} \mathrm{D}_{0}}}\right)
\end{aligned}
$$

The $\kappa$-model can be solved using a measured value of the mean hygroscopic growth factor from the HTDMA. The $\kappa$ value of a multicomponent particle can also be approximated using the ZSR mixing rule (Stokes, 1966) whereby a $\kappa$ value can be calculated from the volume weighted $\kappa_{i}$ 's of a particle's components as shown in Eq. (4), where $\epsilon_{i}$ is the volume fraction of each component.

$\kappa=\sum \epsilon_{i} \kappa_{i}$

In this study $\kappa$ values for the SOA were calculated directly from the unseeded SOA humidograms measured by each HTDMA instrument at different RHs. The $\kappa$ values for ammonium sulphate was calculated from the theoretical $S_{c}\left(D_{0}\right)$ (Topping et al., 2005a). For the seeded experiments the volume fraction of organic and ammonium sulphate seed was calculated from the number size distribution as described in Sect. 2.1. Then using Eq. (4) $\kappa$ was derived for the seeded experiments. The $S_{c}$ for the particles could then be predicted using the $\kappa$-model and compared to the values measured by the $\mathrm{CCN}$ counter.

\section{Results and discussion}

\subsection{HTDMA results: unseeded experiments}

Two unseeded photo-oxidation experiments were performed as detailed in Table 2. The experimental phenomenology was (repeatably) as follows: within two hours, the nucleation of aerosol could be detected using a condensation particle counter (TSI, 3025) with a nominal 50\% detection efficiency at $3 \mathrm{~nm}$. Several hours after nucleation the combined coagulation rate and the loss rate to the chamber walls became greater than the new particle formation rate, after which the formation of new particles quickly decreases to zero. The scanning mobility particle sizer (TSI SMPS, 3080) is was used to estimate the total mass concentration (assuming constant particle sphericity and density of $1300 \mathrm{~kg} \mathrm{~m}^{-3}$ as measured by Alfarra et al. (2006) for $\alpha$-pinene SOA from photooxidation experiments performed previously). Based on the estimated mass detectable condensation of VOC oxidation products continues for at least $8 \mathrm{~h}$ after nucleation. At this stage the mass loss rate equals the mass formation rate, leading to the peak in mass concentration.

The hygroscopic growth factor of the aerosol was measured by the 3 HTDMAs at a constant RH for at least the first 6 to $8 \mathrm{~h}$ of each unseeded experiment (shown in Fig. 2). Comparing the $8.9 \mathrm{ppbv}$ and $37 \mathrm{ppbv}$ experiments a systematic difference in the growth factor of $\sim 0.1$ was measured by $\mathrm{H}_{\text {MAN }}$ and the limited data available from $\mathrm{H}_{\mathrm{QUT}}$ also showed a similar difference in the growth factors, $\mathrm{H}_{\mathrm{PSI}}$ did not see a difference. It has been shown in a previous study (Duplissy et al., 2008) that much larger changes in the initial VOC mixing ratio (i.e. $10 \mathrm{ppbv}$ vs. $250 \mathrm{ppbv}$ ) can lead to substantial differences in hygroscopic growth factors; here we see that relatively small changes in the experimental conditions may have an effect. To mitigate these effects, subsequent investigation of the seeded systems were carried out at a nominal precursor mixing ratio of $10 \mathrm{ppbv}$. The lowest mixing ratio was chosen so as to be nearer atmospheric levels.

In order to provide a parameterisation of the sub-saturated water uptake the growth factor of the pure $\alpha$-pinene SOA was measured at a series of RHs from $\sim 40 \%$ up to the maximum individual each HTDMA would allow (HMAN $92 \%$, $\mathrm{H}_{\text {PSI }} 95 \%$ and $\mathrm{H}_{\mathrm{QUT}}$ 94\%). These humidograms (shown in Fig. 3) were measured after $\sim 6 \mathrm{~h}$ of the experiments once the growth factor and the aerosol mass had stabilised. $\mathrm{Hu}-$ midogram data could therefore be gathered over the remainder of the experiment. The growth factor increases smoothly with increasing RH in agreement with previous studies of this type of system (Duplissy et al., 2008; Varutbangkul et al., 2006) from $10 \% \mathrm{RH}$ upwards (i.e. there is always water associated with the aerosol even at low RHs). There are clear differences in the growth factors measured by the 3 HTDMAs. $\mathrm{H}_{\mathrm{PSI}}$ measures the highest growth factors systematically above the other HTDMAs, whilst $\mathrm{H}_{\text {MAN }}$ and $\mathrm{H}_{\mathrm{QUT}}$ measure growth factors within experimental error of each 


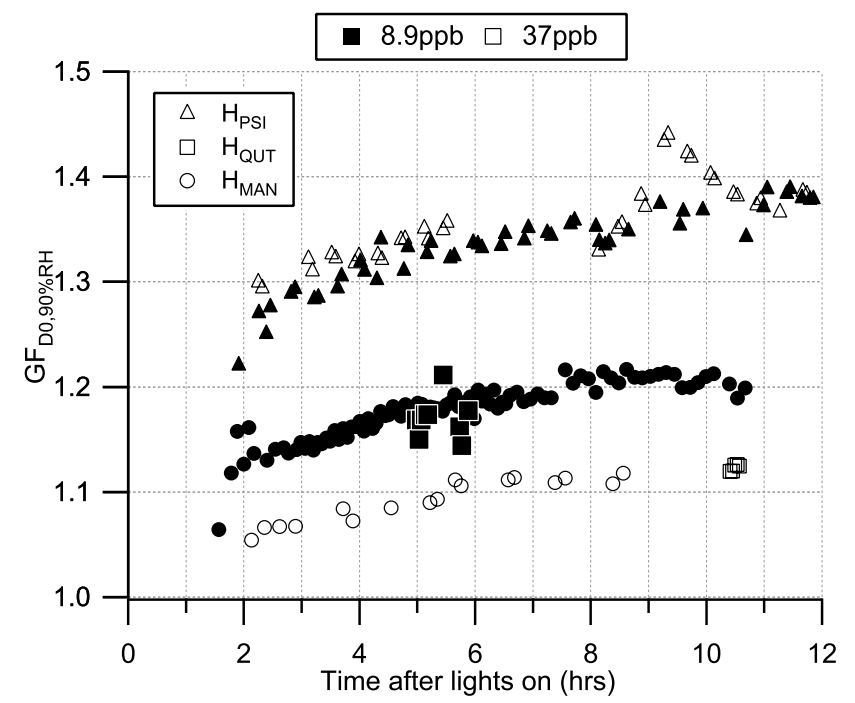

Fig. 2. Unseeded SOA growth factor measurements as a function of time.

other up to $\sim 86 \% \mathrm{RH}$. These differences mean that the $a_{w}$ parameterisations will not be the same. The parameterisation for ADDEM which utilises the full shape of the humidogram will be affected, with all 3 instruments approaching $a_{w}=1$ from a different direction. The $\kappa$ parameterisation will differ between instruments, with agreement dependent on the specific $\mathrm{GF}_{\mathrm{D} 0, \mathrm{RH}}$ used.

It can be seen in Fig. 3 that there is a discrepancy between the 3 HTDMA instruments for the unseeded SOA experiments. Agreement between the instruments and with theory for the pure ammonium sulphate was observed (shown in Fig. 1). Given the agreement for the pure ammonium sulphate experiment we know that the aerosol is being properly humidified to the set point RH and the DMAs are sizing properly (which was also verified using polystyrene latex spheres). There is clearly some property of the SOA produced in the chamber that makes it behave differently depending o the HTDMA by which it was sampled. The specific design differences of these 3 HTDMAs were summarised in Sect. 2.1 and a more detailed overview in given in the supplementary material (http://www.atmos-chem-phys.net/ 10/2577/2010/acp-10-2577-2010-supplement.pdf). These 3 HTDMAs along with 3 others are also discussed in detail in Duplissy et al. (2009). Here we will focus mainly on the consequences of these discrepancies with respect to parameterisation of water uptake from growth factor measurements and the ability to make CCN activation predictions from them. It is worth however discussing some of the possible reasons for the differences. Potential causes of the discrepancy were identified and investigated during the experiments.
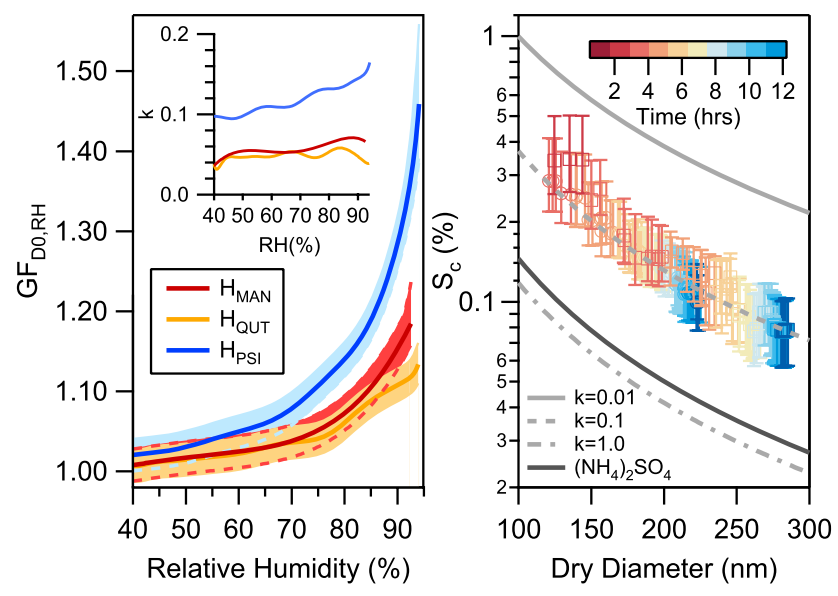

Fig. 3. Unseeded experiments. Left hand side: Humidograms taken by the 3 HTDMAs for the unseeded SOA experiment on the 11th, the shaded bands indicate the sensitivity to the uncertainty in the RH ( $1.5 \%$ for $\mathrm{H}_{\text {MAN/QUT }}$ and $1 \%$ for $\mathrm{H}_{\mathrm{PSI}}$ ). The inset in the left hand panel shows the $\kappa$ values for each HTDMA as a function of RH. Right hand side: $S_{C}$ measured by the CCN counter for the unseeded SOA experiments (coloured circles, $8.9 \mathrm{ppbv}$ and squares, $37 \mathrm{ppbv}$. Also indicated for reference are 3 lines of constant $\kappa$ (at $\kappa=0.01$, 0.10 and 1.0) and pure $\left(\mathrm{NH}_{4}\right)_{2} \mathrm{SO}_{4}$ from ADDEM.

\subsubsection{Conditioning of the aerosol prior to sizing in the first DMA may affect its properties}

$\mathrm{H}_{\text {MAN }}$ sampled the aerosol from the chamber directly into the first DMA, without pre-drying the sample. The first DMA was conditioned to less than $10 \%$ RH by drying the sheath air. The assumption is that the aerosol is sufficiently dry once it enters the sizing region of the DMA where the aerosol dry size is selected. This assumption was tested by placing a diffusion drier intermittently in front of the first DMA during one of the unseeded $\alpha$-pinene experiments. Comparing the measurements no obvious difference was seen. This is not surprising. Given that the aerosol in the chamber is conditioned to $50 \% \mathrm{RH}$ at $20^{\circ} \mathrm{C}$ and the laboratory temperature was typically in excess of $25^{\circ} \mathrm{C}$ meaning that the $\mathrm{RH}$ of the sample will have dropped to less than $37 \% \mathrm{RH}$ prior to entering the first DMA, any artefact would not account for the difference in GF observed. A second test was performed on $\mathrm{H}_{\text {MAN }}$ during an unseeded experiment; the $\mathrm{RH}$ in the second DMA was reduced to less than $10 \%$ and the GF was measured. The resulting GF was $\sim 1.0 \pm 0.01$, indicating that the $\mathrm{RH}$ and the size of the aerosol in the first and second DMAs was the same (i.e. after conditioning the particles for 30s at less than $10 \% \mathrm{RH}$ they do not dry further).

HPSI had a much shorter sampling line to the chamber than $\mathrm{H}_{\mathrm{MAN}}$ and $\mathrm{H}_{\mathrm{QUT}}$ and is in a temperature controlled enclosure. Potentially material may volatilise in the longer, warmer sampling lines altering the properties. It should be 
noted that the $\mathrm{CCN}$ counter was connected to the same inlet as $\mathrm{H}_{\text {MAN }}$ and $\mathrm{H}_{\mathrm{QUT}}$, therefore the $\mathrm{CCN}$ counter's sample would be affected in the same way.

\subsubsection{Conditioning of the aerosol in the humidifier may affect it properties}

$\mathrm{H}_{\text {MAN }}$ and HPSI use a Gore-Tex ${ }^{\circledR}$ membrane with a counter flow of humid air to condition the sample aerosol. $\mathrm{H}_{\text {QUT }}$ used Nafion ${ }^{\circledR}$ membranes to condition both the sheath and sample flows. Therefore we see no link between the humidification method and the discrepancy. HPSI does however obtain humidification by reducing the temperature of the sample between its two DMAs by $\sim 4^{\circ} \mathrm{C}$. So it could be that there is an effect from condensing semi-volatiles in the re-circulating sheath system or that providing a temperature drop is a more efficient humidification process than altering the partial pressure of water on the outside of a membrane alone. However if there were a significant kinetic limitation on the water uptake of the SOA the humidifier with the longest residence time would be expected to grow the particles most fully. This is not observed for these HTDMAs. HMAN had the longest residence time $(\sim 30 \mathrm{~s})$ and $\mathrm{H}_{\mathrm{QUT}}$ had the shortest $(\sim 4 \mathrm{~s})$ and measured similar growth factors. HPSI which gave the highest growth factor had a residence time of $\sim 15 \mathrm{~s}$. For the same type of experiment two different HTDMAs with residence times of $2 \mathrm{~s}$ and $0 \mathrm{~s}$ did show a reduced growth factor compared to $\mathrm{H}_{\mathrm{PSI}}$ consistent with a residence time effect (Duplissy et al., 2009). Sjogren et al. (2007) demonstrated that residence time in the humidifier can alter the measured water uptake depending on the composition, such an explanation is not consistent with $\mathrm{H}_{\mathrm{MAN}}$ having the longest residence time.

\subsection{CCN potential: unseeded experiments}

The right hand panel of Fig. 3 shows the $S_{c}$ at different diameters throughout the experiment derived from the $\mathrm{CCN}$ counter's measurements. Figure 3 shows the $S_{c}$ decreasing with increasing diameter as expected. The higher precursor concentration ( $37 \mathrm{ppb}$ ) experiment nucleated more particles which grew more quickly to larger diameters than the lower concentration experiment, despite this $S_{c}\left(D_{0}\right)$ was within the calculated uncertainty for the two experiments. The measured values are consistent with other studies of $\alpha$-pinene SOA measured in the PSI chamber (Duplissy et al., 2008; Jurányi et al., 2009). No significant change in hygroscopicity is observed with time, indicated by the fact that the measured $S_{c}$ runs almost parallel to the line of constant $\kappa$ shown in Fig. 3. These measured values will be compared to the predictions of the models.

\subsection{Parameterisation of the organic water uptake}

As described in Sect. 2.5.1 ADDEM utilised the full shape of the HTDMA's humidograms to derive the $a_{w}$. Figure 4 shows the parameterised $a_{w}$ for each of the HTDMAs, for

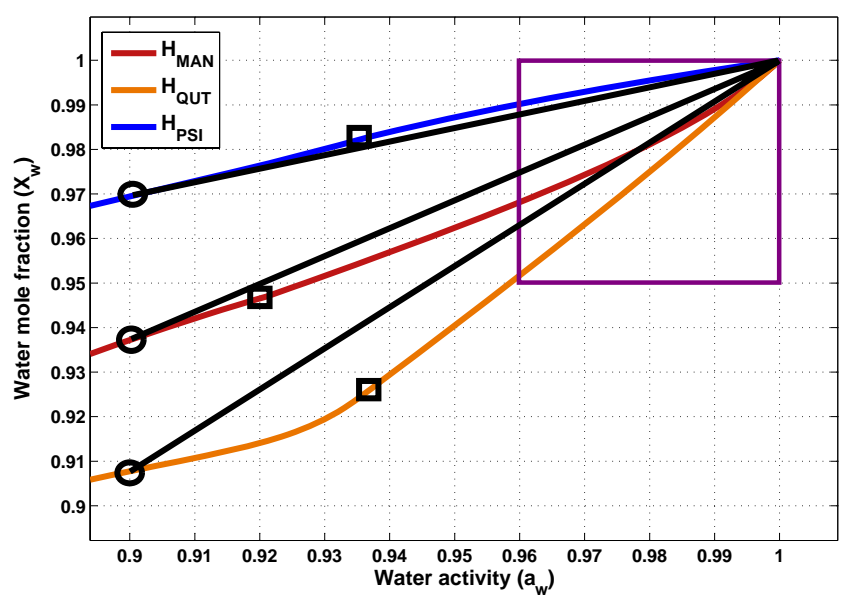

Fig. 4. Water activity curves for the 3 HTDMAs, extended beyond the measurement region to one (black boxes indicate the highest measured value by each HTDMA). The figure illustrates the extrapolations made using ADDEM and the $\kappa$-model, which are required to obtain a value for the water activity when making a prediction of their CCN activity. The black line extending from the point at $a_{w}=90$, shows the difference between the single point derivation and the parameterisation based on the humidogram used by ADDEM. The black squares show the point equivalent to the maximum RH set by the HTDMA.

this illustration a molecular weight of $500 \mathrm{~g} \mathrm{~mol}^{-1}$ and a density of $1300 \mathrm{~kg} \mathrm{~m}^{-3}$ have been used. On each line a black square indicates the highest point on the HTDMA growth factor curves (highest $\mathrm{RH}=$ highest $a_{w}$ neglecting curvature), the shape of the curves below this point is determined by the measured growth factors which in turn determines the trajectory of the interpolation. From this point on the full shape of the growth factor curve has been used to extrapolate toward $a_{w}=1$. Predictions from ADDEM use these lines to predict the critical point. For clarity, a purple box has been inserted around the region where ADDEM might search the $a_{w}$ space whilst converging on the critical point. The $\kappa$-model differs in that one point, often $90 \% \mathrm{RH}$ (as indicated by the black circles in Fig. 4 purely for illustration) is used to extrapolate toward dilute solutions. The black lines extending from the $a_{w}$ at $90 \% \mathrm{RH}$ shows how the $\kappa$ derived $a_{w}$ extends to dilute conditions from the single point. Note how the shape of the humidograms causes the varying deviations from the single point extrapolation.

\subsection{CCN predictions: unseeded experiments}

$\mathrm{CCN}$ activity was predicted for the unseeded $\alpha$-pinene experiments based on the parameterised $a_{w}$ from the 3 different HTDMAs using the ADDEM and $\kappa$-models and is presented in Fig. 5. The 3 rows of panels correspond to the 3 HTDMAs. The ADDEM predictions have been carried out with several different sets of assumed organic component properties. All permutations use the same parameterisation of $a_{w}$ as 
a function of solute concentration derived from the three different HTDMA instruments, as discussed in Sect. 2.5.1. It should be noted that, because the humidograms were taken late in the experiments, the particle dry sizes used to derive $a_{w}$ were above $100 \mathrm{~nm}$.

In the first set of cases the surface tension is assumed to be that of pure water (red triangles). The second set uses the solution concentration dependent surface tension parameterisation (green circles). The ADDEM predictions of $S_{c}$ for the unseeded experiments are made as a function of dry diameter, using $a_{w}$ derived from each HTDMA and a range of realistic molecular weights (200 to $500 \mathrm{~g} \mathrm{~mol}^{-1}$ ) and densities (1200 to $1800 \mathrm{~kg} \mathrm{~m}^{-3}$ ). The bulk to surface partitioning calculation from each HTDMA is plotted as black crosses in Fig. 5.

In the $\kappa$-model simulations, all "hygroscopicity parameters" are supposed to be captured in the $\kappa$ value derived from the HTDMA growth factor measured at a single RH. Calculations are presented using $2 \kappa$ values based on 2 different relative humidities, plotted as yellow squares. The $2 \kappa$ values are from RHs of $80 \%$ and the maximum set by the HTMDA, showing the effect of increasing dilution on the predicted $S_{c}$. The range of the experimental $\mathrm{CCN}$ data is plotted on each graph in blue.

The ADDEM predictions assuming the surface tension of water (red triangles) differ from the $\kappa$-model predictions (orange squares). Using $\kappa$ values calculated from the HTDMA data at higher RHs the predicted $S_{c}$ is closer to ADDEM predicted values. For the data from $\mathrm{H}_{\mathrm{QUT}}$, ADDEM is in agreement at the highest $\mathrm{RH}$, but significantly lower when $\kappa$ is derived at the lower RH. $\kappa$ from $\mathrm{H}_{\mathrm{PSI}}$ increases slightly with $\mathrm{RH}$ (shown in the inset of Fig. 3) however $\kappa$ derived $S_{c}$ is within experimental uncertainty of ADDEM at all RHs. The $a_{w}$ parameterisations from $\mathrm{H}_{\text {MAN }}$ give $\kappa$ predictions lower than ADDEM at all RHs. It is evident that the $\kappa$-model predicted $S_{c}$ can be lower or higher than the ADDEM predictions, depending on the HTDMA used, leading to different conclusions about the possible effects of changing solution concentration on the $a_{w}$. The differences between the models are caused largely by the way the $a_{w}$ parameterisations change with increased dilution (as illustrated in Fig. 4). The inclusion of the surface tension parameterisation in ADDEM reduces the predicted $S_{c}$ significantly for all 3 HTDMA parameterisations.

It was found that the sensitivity of the ADDEM predictions to the molecular weight and density is relatively small compared the other differences in the applied models. The lowest molecular weight $\left(200 \mathrm{~g} \mathrm{~mol}^{-1}\right)$ and highest density $\left(1800 \mathrm{~kg} \mathrm{~m}^{-3}\right)$ gives the highest $S_{c}$ when assuming the surface tension of water, the trend is reversed when the surface tension parameterisation is included.

To recap: $S_{c}$ predictions using $\kappa$ derived from all the HTDMAs converge towards the ADDEM predicted $S_{c}$ at higher RHs when assuming the surface tension of water. For $\mathrm{H}_{\text {MAN }}$, the $\kappa$-model predictions remain outside the uncer- tainty attributable to the growth factor measurements (see supplementary material for details of the measurement uncertainties, http://www.atmos-chem-phys.net/10/2577/2010/ acp-10-2577-2010-supplement.pdf), while for $H_{P S I}$ the difference is within the uncertainty for $\kappa$ calculated at all RHs. For $\mathrm{H}_{\mathrm{QUT}}$ the $\kappa$ values depend relatively strongly on the $\mathrm{GF}_{\mathrm{D} 0, \mathrm{RH}}$ used to calculate them, however the predictions are always above the measured values. ADDEM relies on extrapolated predictions of $a_{w}$ in very dilute regions (beyond that which is measured by the HTDMA). When the RH used to derive $\kappa$ is increased, the same conditions are approached (but not always reached). If a lower $\mathrm{RH}$ is used to derive $\kappa$, the calculations diverge.

The above discussion regarding ADDEM assumes that bulk to surface partitioning can be ignored. Inclusion of this effect accounts for the distribution of material between the bulk and surface layer, influencing the concentration of solute in the Raoult and surfactant in the Kelvin terms. A full discussion of this process is presented in Sorjamaa et al. (2004). The black crosses in Fig. 5 show predicted $S_{c}$ using partitioning calculations to alter the concentrations used within the Raoult and Kelvin terms, but also considering a decrease in surface tension. For $\mathrm{H}_{\mathrm{MAN}}$ and $\mathrm{H}_{\mathrm{QUT}}$ the predictions including partitioning (black crosses) increase the predicted $S_{c}$ compared to considering surface tension reduction alone, however the predicted $S_{c}$ is still less than assuming the surface tension of water in ADDEM and the $\kappa$-model. For $\mathrm{H}_{\mathrm{PSI}}$, the partitioning calculations (black crosses) actually increase $S_{c}$ beyond predictions assuming the surface tension of pure water. The surface tension profile could be altered to make the two lines meet but it is difficult to justify, because the $a_{w}$ profile derived from HPSI combined with an appropriately modified surface tension isotherm is unrealistic. It should also be noted in this case that, the lower the RH from which $\kappa$ was derived, the closer the agreement between the $\kappa$-model and bulk-surface partitioning within ADDEM.

It is the case for each HTDMA that the measured $S_{c}$ (blue lines on Fig. 5) does not follow one of the prediction methods across all sizes, rather each HTDMA's predictions move slightly towards or away from the measured values with increasing diameter. This could be due to the fact that the growth factors used to derive the $a_{w}$ (for both ADDEM and the $\kappa$-model) were measured 8 to $10 \mathrm{~h}$ into the experiment. The hygroscopicity measured by the HTDMAs increases during the first hours of the experiment before stabilising (Duplissy et al., 2009) and as seen in previous experiments in the PSI chamber (Duplissy et al., 2008; Baltensperger et al., 2005). Therefore the derived $a_{w}$ might be expected to underpredict the $S_{c}$ initially. The $S_{c}$ at $100 \mathrm{~nm}$ in Fig. 5 were measured $\sim 3 \mathrm{~h}$ after lights on (Fig. 3 shows the time series). There is insufficient time to measure a full humidogram under stable conditions to provide input to ADDEM during the first hours of the experiments, $\kappa$-model predictions however, result in behavior consistent with the proceeding observations. It may be that the accuracy of the surface 

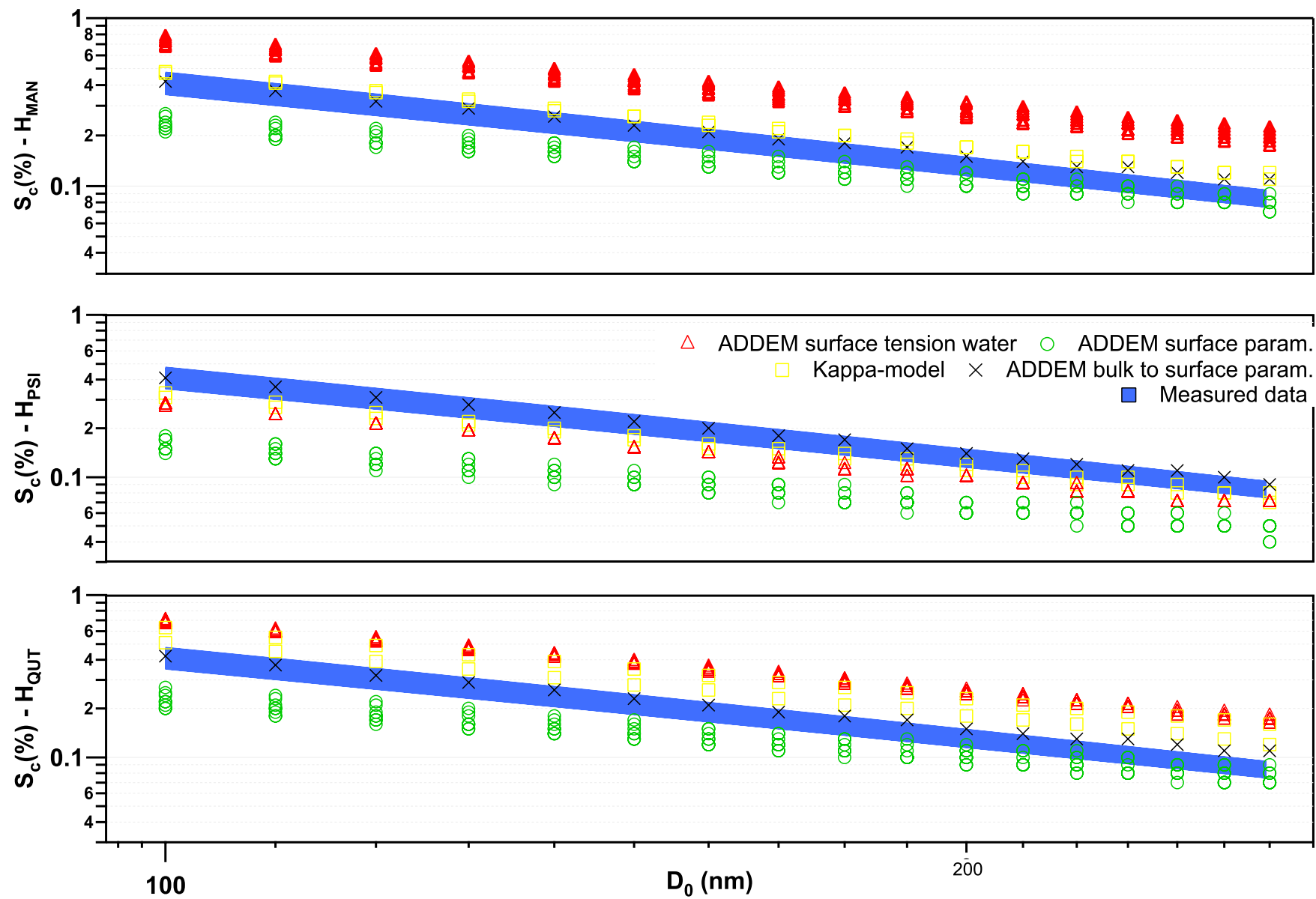

Fig. 5. Pure $\alpha$-pinene SOA experiments: $S_{c}$ predictions using the 3 HTDMAs to parameterise the water activity. Top panel shows $\mathrm{H}_{\mathrm{MAN}}$, the middle panel shows $\mathrm{H}_{\mathrm{QUT}}$ and the bottom panel shows $\mathrm{H}_{\mathrm{PSI}}$. Red triangles are ADDEM predictions for the range of molecular weights and densities assuming the surface tension of water. Green circles are ADDEM predictions with the parameterised organic component surface tension for each molecular weight and density pair. Yellow squares are the $\kappa$-model predictions for $80 \% \mathrm{RH}$ and the highest RH set by each HTDMA. The blue band represents the range of experimental data measured by the CCN counter. The black crosses are the ADDEM predictions incorporating bulk to surface partitioning.

parameterisations varies with diameter for example, but due to the instrument discrepancies this cannot be resolved.

The comparison of the ADDEM and $\kappa$-model simulations with the measured $S_{c}$ for the unseeded experiments can be summarised as follows:

i. using $a_{w}$ derived from $\mathrm{H}_{\text {MAN }}$ the ADDEM predictions agree with the CCN counter data within measurement error when the reduced surface tension profile is applied. For particles with smaller diameters earlier in the experiments the bulk to surface partitioning calculations give agreement within experimental error, but diverge as the experiments progress. $\kappa$-model predictions with $\kappa$ derived from the growth factor are always above the measured values. ADDEM predictions assuming the surface tension of water do not represent the CCN counter data within the calculated uncertainties. ii. using $a_{w}$ derived from $\mathrm{H}_{\mathrm{QUT}}$ the ADDEM predictions agree with the $\mathrm{CCN}$ counter data within measurement error when the reduced surface tension profile is applied and when bulk to surface partitioning is considered. The $\kappa$ predictions from the measured growth factors and the ADDEM predictions assuming the surface tension of water are outside of the measured data uncertainty.

iii. for $a_{w}$ derived from $\mathrm{H}_{\mathrm{PSI}}$, the experimental $\mathrm{CCN}$ data agree with the $\kappa$-model and ADDEM using the surface tension of water within the uncertainty of the measured values. ADDEM including bulk to surface partitioning predicts $S_{c}$ within the uncertainty of the measured $S_{c}$. ADDEM predictions with reduced surface tension alone under-predict $S_{c}$. 


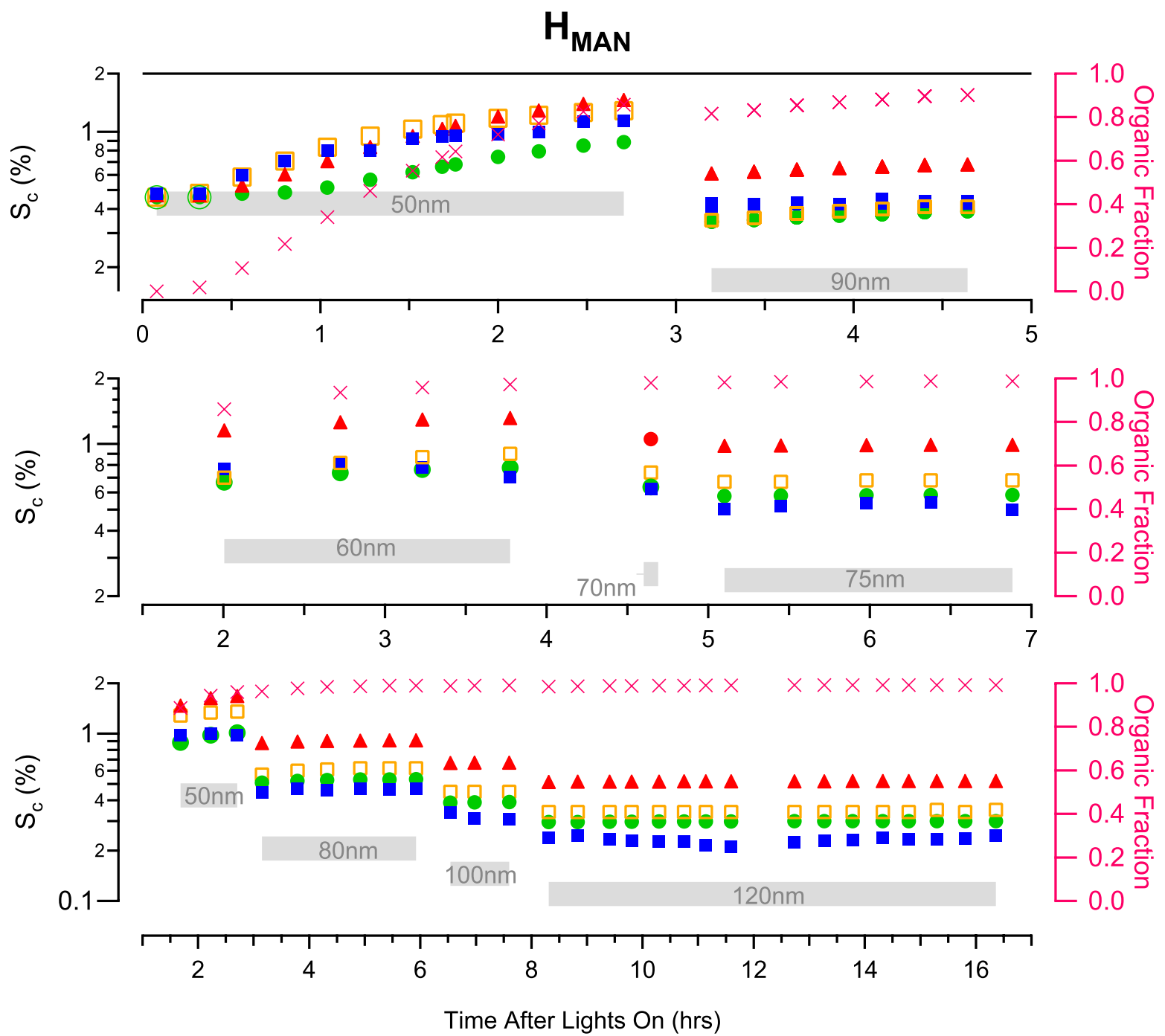

Fig. 6. Seeded experiments $-S_{c}$ predictions from the $\mathrm{H}_{\mathrm{MAN}}$ parameterisations. The 3 panels correspond to different experiments; 28th (top), 22nd (middle) and 17th (bottom) The 3 panels show $S_{c}$ predicted using ADDEM with the surface tension of water (red triangles), ADDEM including surface tension suppression (green circles) and the $\kappa$-model (orange squares). The measured $S_{c}$ values are shown (blue squares) and pure ammonium sulphate is also shown for reference for the selected dry size (grey lines). The right hand axis shows the organic fraction (pink crosses).

\subsection{CCN potential: seeded experiments}

A series of experiments were conducted using an ammonium sulphate seed aerosol in the chamber (under the conditions outlined in Table 2). The $S_{c}$ measured by the CCN counter in these experiments are shown in Figs. 6, 7 and 8 (blue squares). For the seeded experiments the $\mathrm{CCN}$ counter was operated with a DMA upstream as described in the experimental section. At the start of the experiments the $S_{c}$ measured was consistent with those expected from the ammonium sulphate seed alone, $S_{c}$ as a function of dry diameter predicted using ADDEM is shown for the seed (grey bars) and is initially transected by the measured CCN data. As the experiments progress the semi-volatile reaction product of the $\alpha$-pinene condense into the aerosol phase. Careful choice of the seed surface area meant that condensation onto the seed dominated the organic aerosol formation and nucleation was not observed.

As the fraction of newly condensed material increases with time we saw a corresponding increase in the $S_{c}$ due to the less hygroscopic nature of the organic material. After 3 to $4 \mathrm{~h}$ $S_{c}\left(D_{0}\right)$ was similar to the values observed in the unseeded SOA experiments. This is expected as the particles are now nearly $100 \%$ organic, but it does indicate that the oxidation of the VOC in both the unseeded and seeded cases took place at a similar rate. 

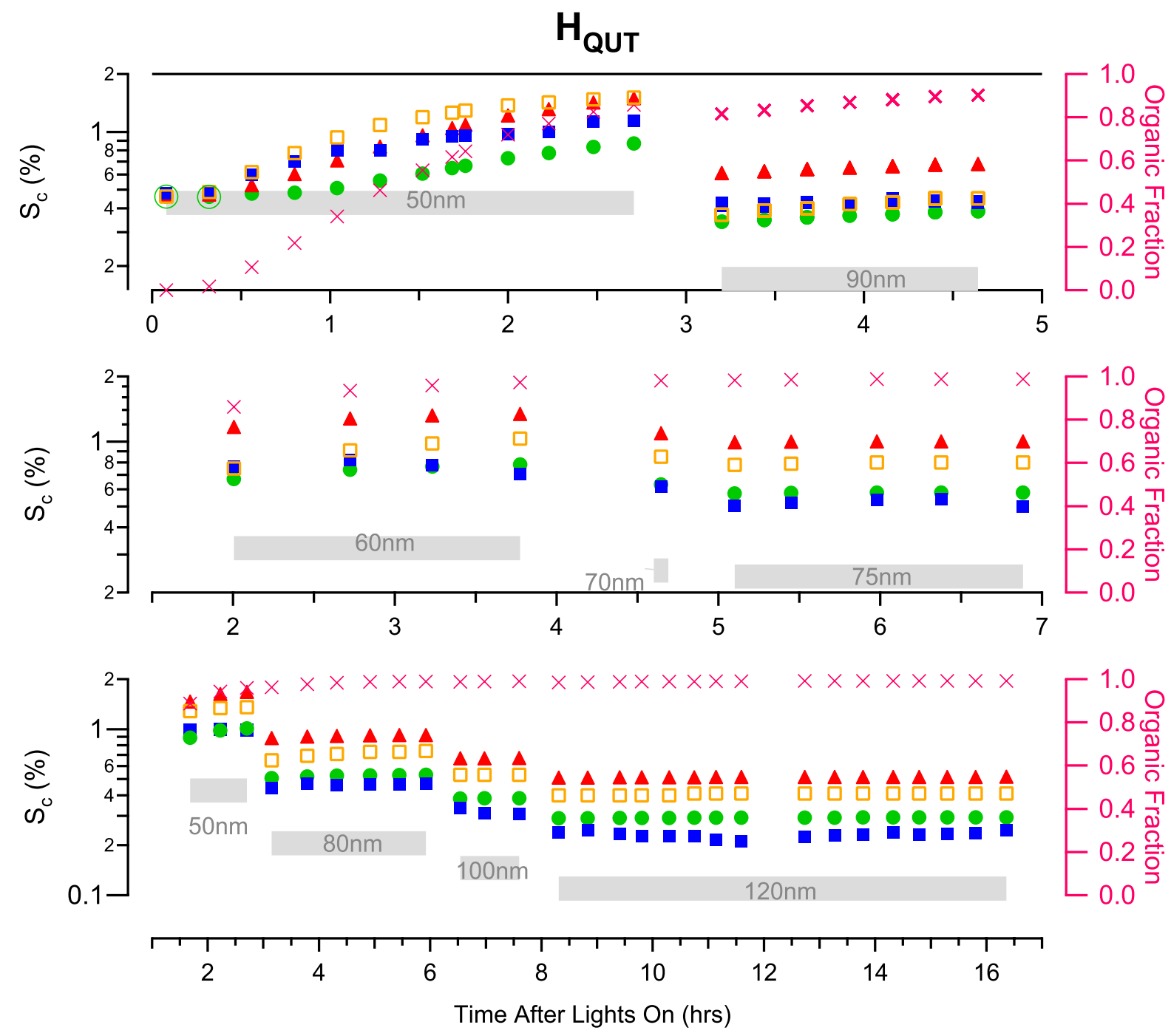

Fig. 7. Seeded experiments $-S_{c}$ predictions from the $\mathrm{H}_{\mathrm{QUT}}$ parameterisations. The 3 panels correspond to different experiments; 28th (top), 22nd (middle) and 17th (bottom) The 3 panels show $S_{c}$ predicted using ADDEM with the surface tension of water (red triangles), ADDEM including surface tension suppression (green circles) and the $\kappa$-model (orange squares). The measured $S_{c}$ values are shown (blue squares) and pure ammonium sulphate is also shown for reference for the selected dry size (grey lines). The right hand axis shows the organic fraction (pink crosses).

\subsection{Parameterisation of the sub-saturated water uptake and CCN predictions: seeded experiments}

The mixed organic/inorganic $\mathrm{CCN}$ activity predicted from ADDEM and the $\kappa$-model using the organic parameterisations derived from the HTDMA measurements in the unseeded experiments is compared to the CCN potential measured during the seeded experiments. Figures 6, 7 and 8 show a comparison of predicted and measured $S_{c}$ values for the seeded experiments corresponding to predictions made using the data from the 3 different HTDMA instruments. On each panel there are 3 subplots corresponding to the 3 seeded experiments. The $\mathrm{x}$-axis shows the "time after lights on" and the right hand y-axis shows the calculated organic mass fraction (using SMPS data) which is plotted as pink crosses. The ADDEM predictions (using a molar mass of $500 \mathrm{~g} \mathrm{~mol}^{-1}$ and density of $1300 \mathrm{~kg} \mathrm{~m}^{-3}$ ) using the surface tension of water are shown in red and using the mixture surface tension are shown in green. For the $\kappa$-model, the $\kappa$ values for the organic fraction were taken from the HTDMA data from the unseeded experiments at $90 \% \mathrm{RH}$, the $\kappa$ values for the inorganic fraction were taken from ADDEM predictions of pure ammonium sulphate at the point of activation. The $\kappa$ predictions are shown as orange squares. The experimentally determined $S_{c}$ values are shown as blue circles. 


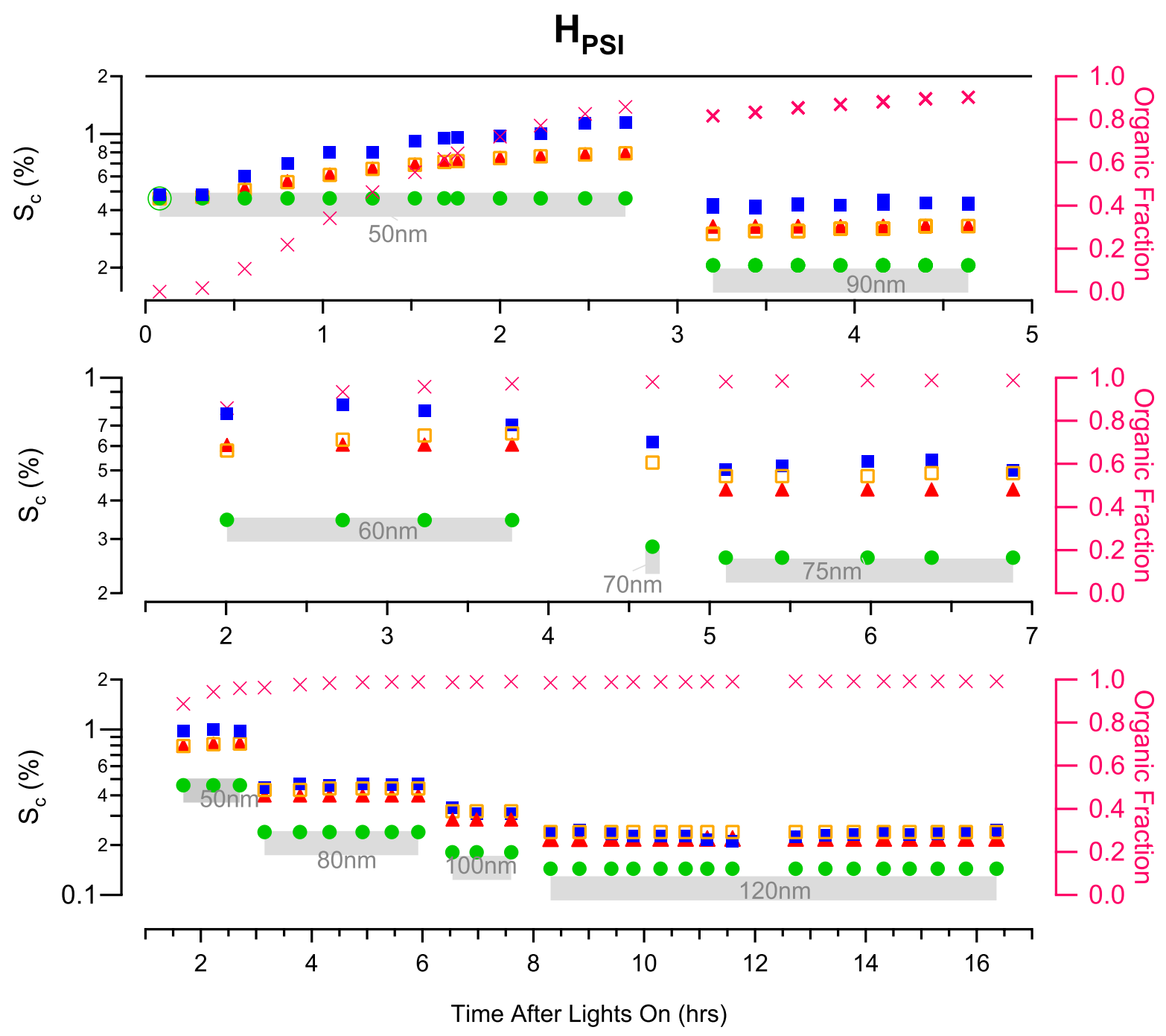

Fig. 8. Seeded experiments $-S_{c}$ predictions from the $\mathrm{H}_{\mathrm{PSI}}$ parameterisations. The 3 panels correspond to different experiments; 28th (top), 22nd (middle) and 17th (bottom) The 3 panels show $S_{c}$ predicted using ADDEM with the surface tension of water (red triangles), ADDEM including surface tension suppression (green circles) and the $\kappa$-model (orange squares). The measured $S_{c}$ values are shown (blue squares) and pure ammonium sulphate is also shown for reference for the selected dry size (grey lines). The right hand axis shows the organic fraction (pink crosses).

For each HTDMA the CCN activity and model agreement tends towards that observed for the unseeded experiments as the organic fraction and dry size of the particles increases. The measured $S_{c}\left(\mathrm{D}_{0}\right)$ increases significantly as the organic fraction increases from 0 for the $50 \mathrm{~nm}$ particles in the top panels of Figs. 6, 7 and 8, the addition of the organic material reducing the hygroscopicity. Comparing the model predictions to the measured data when the organic fraction is less than $\sim 70 \%$, ADDEM assuming the surface tension of water and the $\kappa$-model gives the best agreement for $\mathrm{H}_{\mathrm{MAN}}$ and $\mathrm{H}_{\mathrm{QUT}}$, whilst the $a_{w}$ from $\mathrm{H}_{\mathrm{PSI}}$ predicts $S_{c}$ that are always lower than the measured values. That is the measured gradient in $S_{c}$ as a function of increasing diameter is greater than that of any of the prediction methods, indicating a significant change in hygroscopicity with time. This is consistent with the fact that all prediction methods used hygroscopicity derived later in the experiment as mentioned in Sect. 3.4.

For $\mathrm{H}_{\mathrm{MAN}}$ and $\mathrm{H}_{\mathrm{QUT}}$ the $\kappa$-model predictions sometimes fall on top of the ADDEM predictions with surface tension suppression (notably at $90 \mathrm{~nm}$ ). This is because the change in the $a_{w}$ from $90 \% \mathrm{RH}$ to the point of activation used in ADDEM compared to the $\kappa$-model is cancelled out by the surface tension reduction.

When the organic fraction is greater than $\sim 80 \%$ the behavior is similar to the unseeded experiments. The $a_{w}$ derived from $\mathrm{H}_{\text {MAN }}$ gives the best predictions when using ADDEM with the inclusion of the reduced surface tension profile. The $\kappa$-model predictions from $\mathrm{H}_{\mathrm{MAN}}$ tends to over-predict the $S_{c}$ 
increasingly the larger the organic fraction. Assuming the surface tension of water in ADDEM consistently overpredicts the $S_{c}$ for $\mathrm{H}_{\text {MAN }}$. The $a_{w}$ derived from $\mathrm{H}_{\mathrm{QUT}}$ gives the best predictions when using ADDEM with the inclusion of the reduced surface tension profile. Both the $\kappa$-model and ADDEM predictions from $\mathrm{H}_{\mathrm{QUT}}$ overpredict the $S_{c}$. Using $a_{w}$ and $\kappa$ derived from $\mathrm{H}_{\mathrm{PSI}}$ (Fig. 8), the $\kappa$-model and ADDEM give agreement with the measured $S_{c}$, whereas the inclusion of a reduced surface tension profile leads to an underprediction of $S_{c}$.

\section{Conclusions}

Results from the experiments suggest that predictions of CCN activity made from $\mathrm{H}_{\mathrm{MAN}}$ and $\mathrm{H}_{\mathrm{QUT}}$ compare well with the experimental data when employing the full complexity approach used within ADDEM along with a surface tension parameterisation based on fulvic acid. However, predictions made from $\mathrm{H}_{\mathrm{PSI}}$ compare well using either the ADDEM model and assuming the surface tension of water or the $\kappa$-model. Incorporating bulk to surface partitioning in ADDEM predicts $S_{c}$ values within experimental uncertainty for all 3 HTDMAs (see supplementary material for full details of the measurement uncertainties, http://www.atmos-chem-phys.net/10/2577/2010/ acp-10-2577-2010-supplement.pdf). However, results from $\mathrm{H}_{\mathrm{PSI}}$ are unique in that partitioning calculations cause predictions to be higher than the results from ADDEM combined with assumption of using the surface tension of pure water. Previously, when $a_{w}$ has been calculated from a purely theoretical basis, the opposite has been found. This is a result of the relatively high hygroscopicity measured using $\mathrm{H}_{\mathrm{PSI}}$ combined with an inappropriate proxy for the surfactant behavior in this case study. It would be possible to match the experimental data to the full complexity model outputs by varying the surface tension profile or find an "optimum" $\kappa$ value (by choosing a value at the RH which matches best). However, these "optimum" fitted parameters will be instrument dependent.

Overall it would appear that variability across instruments measuring the growth factor of the same "pure SOA", used as an input to drive model predictions across the whole range of current theoretical complexities, is enough to restrict our ability to say with any confidence which process, or combination of processes, is important. This can be restated that there are too many free parameters which cannot be teased apart using a combination of the HTDMA and CCN instrument. This results from the inadequate accuracy of the HTDMA and its range of application (not a high enough RH).

The fact that 3 HTDMAs measuring the same organic aerosol produced quite different parameterisations of the $a_{w}$ makes it impossible to predict with confidence the cloud activation potential of the aerosol from the hygroscopic growth factor alone using any of the models. Depending on which HTDMA's data is considered a different conclusion is reached as to which parameter the point of activation into a cloud droplet is most sensitive to. Tools such as ADDEM were not designed to rely on data derived from HTDMAs, the variation in critical points resulting from such a treatment being substantial. On the other hand, the $\kappa$-model was designed to work with precisely this sort of data yet the results are extremely instrument dependent. Despite all 3 HTDMAs sampling the same aerosol, its treatment within the instrument results in different measured growth factors outside the perceived measurement uncertainty. This discrepancy could not be explained by any obvious instrumental differences and was unique to the SOA generated in the photo-oxidation chamber.

Previous studies of SOA have identified that the CCN activity is higher than might be expected from the observed sub-saturated water uptake (Prenni et al., 2007; Engelhart et al., 2008). It has been shown that a change in solution non-ideality can account for this discrepancy (Wex et al., 2009; Petters et al., 2009), an important step towards closing the gap between observations and understanding of SOA properties. Without the ability to measure above $\sim 98 \% \mathrm{RH}$ (Hennig et al., 2005) HTDMAs cannot directly probe this effect. Measurements of hygroscopic growth at higher RHs (e.g. Ziese et al., 2008; Wex et al., 2009) could give more information on the $a_{w}$ approaching the point of cloud activation. In the present study it is shown that the $a_{w}$ profiles derived from the HTDMA measurements depend on the instrument used, allowing different conclusions to be reached surrounding the importance of the various terms in the Köhler equation when considered separately.

The current study clearly demonstrates that uncertainties in the measurements of $\alpha$-pinene SOA using current HTDMA instrumentation cannot be reconciled with $\mathrm{CCN}$ measurements using consistent assumptions for aerosol properties. It may be concluded that there is a wide gap between the properties of the SOA particles derived from detailed interpretation of measurements from different combinations of instruments, which are demonstrably capable of resolving inorganic aerosol behavior. In the real atmosphere, there may be a significant and variable contribution from both inorganic and organic components. Whilst assuming conventional values for hygroscopicity of organic material, for the purposes of the Raoult contribution, one might expect $S_{c}$ to be dominated by the inorganic to organic ratio, the degree to which surface tension suppression may play a role could be significant but cannot be resolved using the approach outlined here. Furthermore, the difference between whether the atmospheric organic material is as hygroscopic as the chamber SOA measured by $\mathrm{H}_{\mathrm{PSI}}$ or less so as measured by $\mathrm{H}_{\mathrm{MAN}}$ and $\mathrm{H}_{\text {QUT }}$ will determine the importance of the organic material through it's impact on the Raoult term of the Köhler equation. 
Acknowledgements. This work was supported by the EC projects ACCENT and EUROCHAMP, the European Science Foundation project INTROP as well as the Swiss National Science Foundation. NG was supported by a NERC studentship (ner/s/a2005/13221). We thank Heinz Burtscher (FHNW) for providing the electrospray generator.

Edited by: W. E. Asher

\section{References}

AAlfarra, M. R., Paulsen, D., Gysel, M., Garforth, A. A., Dommen, J., Prévôt, A. S. H., Worsnop, D. R., Baltensperger, U., and Coe, H.: A mass spectrometric study of secondary organic aerosols formed from the photooxidation of anthropogenic and biogenic precursors in a reaction chamber, Atmos. Chem. Phys., 6, 52795293, 2006,

http://www.atmos-chem-phys.net/6/5279/2006/.

Andreae, M. O., Browell, E. V., Garstang, M., Gregory, G. L., Harriss, R. C., Hill, G. F., Jacob, D. J., Pereira, M. C., Sachse, G. W., Setzer, A. W., Dias, P. L. S., Talbot, R. W., Torres, A. L., and Wofsy, S. C.: Biomass-Burning Emissions and Associated Haze Layers over Amazonia, J. Geophys. Res.-Atmos., 93, 1509-1527, 1988.

Baltensperger, U., Kalberer, M., Dommen, J., Paulsen, D., Alfarra, M. R., Coe, H., Fisseha, R., Gascho, A., Gysel, M., Nyeki, S., Sax, M., Steinbacher, M., Prévôt, A. S. H., Sjoren, S., Weingartner, E., and Zenobi, R.: Secondary organic aerosols from anthropogenic and biogenic precursors, Faraday Discuss., 130, 265-278, 2005.

Biskos, G., Malinowski, A., Russell, L. M., Buseck, P. R., and Martin, S. T.: Nanosize effect on the deliquescence and the efflorescence of sodium chloride particles, Aerosol Sci. Technol., 40, 97-106, 2006.

Carter, W. P. L., Cocker, D. R., Fitz, D. R., Malkina, I. L., Bumiller, K., Sauer, C. G., Pisano, J. T., Bufalino, C., and Song, C.: A new environmental chamber for evaluation of gas-phase chemical mechanisms and secondary aerosol formation, Atmos. Environ., 39, 7768-7788, 2005.

Cubison, M. J., Coe, H., and Gysel, M.: A modified hygroscopic tandem DMA and a data retrieval method based on optimal estimation, J. Aerosol Sci., 36, 846-865, 2005.

Duplissy, J., Gysel, M., Alfarra, M. R., Dommen, J., Metzger, A., Prévôt, A. S. H., Weingartner, E., Laaksonen, A., Raatikainen, T., Good, N., Turner, S. F., McFiggans, G., and Baltensperger, U.: Cloud forming potential of secondary organic aerosol under near atmospheric conditions, Geophys. Res. Lett., 35, L03818, doi:10.1029/2007GL031075, 2008.

Duplissy, J., Gysel, M., Sjogren, S., Meyer, N., Good, N., Kammermann, L., Michaud, V., Weigel, R., Martins dos Santos, S., Gruening, C., Villani, P., Laj, P., Sellegri, K., Metzger, A., McFiggans, G. B., Wehrle, G., Richter, R., Dommen, J., Ristovski, Z., Baltensperger, U., and Weingartner, E.: Intercomparison study of six HTDMAs: results and recommendations, Atmos. Meas. Tech., 2, 363-378, 2009,

http://www.atmos-meas-tech.net/2/363/2009/.
Engelhart, G. J., Asa-Awuku, A., Nenes, A., and Pandis, S. N.: CCN activity and droplet growth kinetics of fresh and aged monoterpene secondary organic aerosol, Atmos. Chem. Phys., 8, 3937-3949, 2008,

http://www.atmos-chem-phys.net/8/3937/2008/.

Forster, P., Ramaswamy, V., Artaxo, P., Berntsen, T., Betts, R., Fahey, D., Haywood, J., Lean, J., Lowe, D., Myhre, G., Nganga, J., Prinn, R., Raga, G., M., S., and R., V. D.: Changes in Atmospheric Constituents and in Radiative Forcing. In: Climate Change 2007: The Physical Science Basis. Contribution of Working Group I to the Fourth Assessment Report of the Intergovernmental Panel on Climate Change, Cambridge University Press, Cambridge, 2007.

Gysel, M., McFiggans, G., and Coe, H.: Inversion of tandem differential mobility analyser (TDMA) measurements, J. Aerosol Sci., 40, 134-151, 2009.

Hallquist, M., Wenger, J. C., Baltensperger, U., Rudich, Y., Simpson, D., Claeys, M., Dommen, J., Donahue, N. M., George, C., Goldstein, A. H., Hamilton, J. F., Herrmann, H., Hoffmann, T., Iinuma, Y., Jang, M., Jenkin, M. E., Jimenez, J. L., Kiendler-Scharr, A., Maenhaut, W., McFiggans, G., Mentel, Th. F., Monod, A., Prévôt, A. S. H., Seinfeld, J. H., Surratt, J. D., Szmigielski, R., and Wildt, J.: The formation, properties and impact of secondary organic aerosol: current and emerging issues, Atmos. Chem. Phys., 9, 5155-5236, 2009, http://www.atmos-chem-phys.net/9/5155/2009/.

Haywood, J. and Boucher, O.: Estimates of the direct and indirect radiative forcing due to tropospheric aerosols: A review, Rev. Geophys., 38, 513-543, 2000.

Heald, C. L., Goldstein, A. H., Allan, J. D., Aiken, A. C., Apel, E., Atlas, E. L., Baker, A. K., Bates, T. S., Beyersdorf, A. J., Blake, D. R., Campos, T., Coe, H., Crounse, J. D., DeCarlo, P. F., de Gouw, J. A., Dunlea, E. J., Flocke, F. M., Fried, A., Goldan, P., Griffin, R. J., Herndon, S. C., Holloway, J. S., Holzinger, R., Jimenez, J. L., Junkermann, W., Kuster, W. C., Lewis, A. C., Meinardi, S., Millet, D. B., Onasch, T., Polidori, A., Quinn, P. K., Riemer, D. D., Roberts, J. M., Salcedo, D., Sive, B., Swanson, A. L., Talbot, R., Warneke, C., Weber, R. J., Weibring, P., Wennberg, P. O., Worsnop, D. R., Wittig, A. E., Zhang, R., Zheng, J., and Zheng, W.: Total observed organic carbon (TOOC) in the atmosphere: a synthesis of North American observations, Atmos. Chem. Phys., 8, 2007-2025, 2008, http://www.atmos-chem-phys.net/8/2007/2008/.

Hennig, T., Massling, A., Brechtel, F. J., and Wiedensohler, A.: A tandem DMA for highly temperature-stabilized hygroscopic particle growth measurements between $90 \%$ and $98 \%$ relative humidity, J. Aerosol Sci., 36, 1210-1223, 2005.

Jenkin, M. E.: Modelling the formation and composition of secondary organic aerosol from $\alpha$ - and $\beta$-pinene ozonolysis using MCM v3, Atmos. Chem. Phys., 4, 1741-1757, 2004, http://www.atmos-chem-phys.net/4/1741/2004/.

Johnson, G. R., Fletcher, C., Meyer, N., Modini, R., and Ristovski, Z. D.: A robust, portable H-TDMA for field use, J. Aerosol Sci., 39, 850-861, 2008.

Jurányi, Z., Gysel, M., Duplissy, J., Weingartner, E., Tritscher, T., Dommen, J., Henning, S. Ziese, M., Kiselev, A., Stratmann, K., and George, I., and Baltensperger, U.: Influence of gasto-particle partitioning on the hygroscopic and droplet activation behaviour of $\alpha$-pinene secondary organic aerosol, Phys. Chem. 
Chem. Phys., 11, 8091-8097, doi:10.1039/b904162a, 2009.

Kanakidou, M., Seinfeld, J. H., Pandis, S. N., Barnes, I., Dentener, F. J., Facchini, M. C., Van Dingenen, R., Ervens, B., Nenes, A., Nielsen, C. J., Swietlicki, E., Putaud, J. P., Balkanski, Y., Fuzzi, S., Horth, J., Moortgat, G. K., Winterhalter, R., Myhre, C. E. L., Tsigaridis, K., Vignati, E., Stephanou, E. G., and Wilson, J.: Organic aerosol and global climate modelling: a review, Atmos. Chem. Phys., 5, 1053-1123, 2005, http://www.atmos-chem-phys.net/5/1053/2005/.

Köhler, H.: The Nucleus In and the Growth of Hygroscopic Droplets, T. Faraday Soc., 32, 1152-1161, 1936.

Kreidenweis, S. M., Koehler, K., DeMott, P. J., Prenni, A. J., Carrico, C., and Ervens, B.: Water activity and activation diameters from hygroscopicity data - Part I: Theory and application to inorganic salts, Atmos. Chem. Phys., 5, 1357-1370, 2005, http://www.atmos-chem-phys.net/5/1357/2005/.

McFiggans, G., Artaxo, P., Baltensperger, U., Coe, H., Facchini, M. C., Feingold, G., Fuzzi, S., Gysel, M., Laaksonen, A., Lohmann, U., Mentel, T. F., Murphy, D. M., O’Dowd, C. D., Snider, J. R., and Weingartner, E.: The effect of physical and chemical aerosol properties on warm cloud droplet activation, Atmos. Chem. Phys., 6, 2593-2649, 2006, http://www.atmos-chem-phys.net/6/2593/2006/.

Meyer, N. K., Duplissy, J., Gysel, M., Metzger, A., Dommen, J., Weingartner, E., Alfarra, M. R., Prevot, A. S. H., Fletcher, C., Good, N., McFiggans, G., Jonsson, Å. M., Hallquist, M., Baltensperger, U., and Ristovski, Z. D.: Analysis of the hygroscopic and volatile properties of ammonium sulphate seeded and unseeded SOA particles, Atmos. Chem. Phys., 9, 721-732, 2009, http://www.atmos-chem-phys.net/9/721/2009/.

Middlebrook, A. M., Murphy, D. M., and Thomson, D. S.: Observations of organic material in individual marine particles at Cape Grim during the First Aerosol Characterization Experiment (ACE 1), J. Geophys. Res.-Atmos., 103, 16475-16483, 1998.

Paulsen, D., Dommen, J., Kalberer, M., Prévôt, A. S. H., Richter, R., Sax, M., Steinbacher, M., Weingartner, E., and Baltensperger, U.: Secondary organic aerosol formation by irradiation of 1,3,5trimethylbenzene- $\mathrm{NO}_{\mathrm{X}}-\mathrm{H}_{2} \mathrm{O}$ in a new reaction chamber for atmospheric chemistry and physics, Environ. Sci. Technol., 39, 2668-2678, 2005.

Petters, M. D. and Kreidenweis, S. M.: A single parameter representation of hygroscopic growth and cloud condensation nucleus activity, Atmos. Chem. Phys., 7, 1961-1971, 2007, http://www.atmos-chem-phys.net/7/1961/2007/.

P Petters, M. D., Wex, H., Carrico, C. M., Hallbauer, E., Massling, A., McMeeking, G. R., Poulain, L., Wu, Z., Kreidenweis, S. M., and Stratmann, F.: Towards closing the gap between hygroscopic growth and activation for secondary organic aerosol Part 2: Theoretical approaches, Atmos. Chem. Phys., 9, 3999-4009, 2009, http://www.atmos-chem-phys.net/9/3999/2009/.

Prenni, A. J., Petters, M. D., Kreidenweis, S. M., DeMott, P. J., and Ziemann, P. J.: Cloud droplet activation of secondary organic aerosol, J. Geophys. Res.-Atmos., 112, D10223, doi:10.1029/2006JD007963, 2007.

Presto, A. A., Hartz, K. E. H., and Donahue, N. M.: Secondary organic aerosol production from terpene ozonolysis. 1. Effect of UV radiation, Environ. Sci. Technol., 39, 7036-7045, 2005a.
Presto, A. A., Hartz, K. E. H., and Donahue, N. M.: Secondary organic aerosol production from terpene ozonolysis. 2. Effect of NOx concentration, Environ. Sci. Technol., 39, 7046-7054, 2005 b.

Roberts, G. C. and Nenes, A.: A continuous-flow streamwise thermal-gradient $\mathrm{CCN}$ chamber for atmospheric measurements, Aerosol Sci. Technol., 39, 206-221, 2005.

Seinfeld, J. H., Erdakos, G. B., Asher, W. E., and Pankow, J. F.: Modeling the formation of secondary organic aerosol (SOA). 2. The predicted effects of relative humidity on aerosol formation in the alpha-pinene-, beta-pinene-, sabinene-, Delta(3)-Carene, and cyclohexene-ozone systems, Environ. Sci. Technol., 35, 1806-1817, 2001.

Sjogren, S., Gysel, M., Weingartner, E., Baltensperger, U., Cubison, M. J., Coe, H., Zardini, A. A., Marcolli, C., Krieger, U. K., and Peter, T.: Hygroscopic growth and water uptake kinetics of twophase aerosol particles consisting of ammonium sulfate, adipic and humic acid mixtures, J. Aerosol Sci., 38, 157-171, 2007.

Sorjamaa, R., Svenningsson, B., Raatikainen, T., Henning, S., Bilde, M., and Laaksonen, A.: The role of surfactants in Köhler theory reconsidered, Atmos. Chem. Phys., 4, 2107-2117, 2004, http://www.atmos-chem-phys.net/4/2107/2004/.

Stokes, R. H. Robinson, R. A.: Interactions in aquous nonelectrolyte solutions I. Solute-solvent equilibria, J. Phys. Chem., 70, 2126-2130, 1966.

Topping, D. O., McFiggans, G. B., and Coe, H.: A curved multicomponent aerosol hygroscopicity model framework: Part 1 - Inorganic compounds, Atmos. Chem. Phys., 5, 1205-1222, 2005a.

Topping, D. O., McFiggans, G. B., and Coe, H.: A curved multicomponent aerosol hygroscopicity model framework: Part $2-$ Including organic compounds, Atmos. Chem. Phys., 5, 1223 1242, 2005b.

Topping, D. O., McFiggans, G. B., Kiss, G., Varga, Z., Facchini, M. C., Decesari, S., and Mircea, M.: Surface tensions of multicomponent mixed inorganic/organic aqueous systems of atmospheric significance: measurements, model predictions and importance for cloud activation predictions, Atmos. Chem. Phys., 7, 2371-2398, 2007, http://www.atmos-chem-phys.net/7/2371/2007/.

Varutbangkul, V., Brechtel, F. J., Bahreini, R., Ng, N. L., Keywood, M. D., Kroll, J. H., Flagan, R. C., Seinfeld, J. H., Lee, A., and Goldstein, A. H.: Hygroscopicity of secondary organic aerosols formed by oxidation of cycloalkenes, monoterpenes, sesquiterpenes, and related compounds, Atmos. Chem. Phys., 6, 23672388, 2006, http://www.atmos-chem-phys.net/6/2367/2006/.

Wex, H., Petters, M. D., Carrico, C. M., Hallbauer, E., Massling, A., McMeeking, G. R., Poulain, L., Wu, Z., Kreidenweis, S. M., and Stratmann, F.: Towards closing the gap between hygroscopic growth and activation for secondary organic aerosol: Part 1 Evidence from measurements, Atmos. Chem. Phys., 9, 39873997, 2009,

http://www.atmos-chem-phys.net/9/3987/2009/. 
Zhang, Q., Jimenez, J. L., Canagaratna, M. R., Allan, J. D., Coe, H., Ulbrich, I., Alfarra, M. R., Takami, A., Middlebrook, A. M., Sun, Y. L., Dzepina, K., Dunlea, E., Docherty, K., DeCarlo, P. F., Salcedo, D., Onasch, T., Jayne, J. T., Miyoshi, T., Shimono, A., Hatakeyama, S., Takegawa, N., Kondo, Y., Schneider, J., Drewnick, F., Borrmann, S., Weimer, S., Demerjian, K., Williams, P., Bower, K., Bahreini, R., Cottrell, L., Griffin, R. J., Rautiainen, J., Sun, J. Y., Zhang, Y. M., and Worsnop, D. R.: Ubiquity and dominance of oxygenated species in organic aerosols in anthropogenically-influenced Northern Hemisphere midlatitudes, Geophys. Res. Lett., 34, L13801, doi:10.1029/2007GL029979, 2007.
Ziese, M., Wex, H., Nilsson, E., Salma, I., Ocskay, R., Hennig, T., Massling, A., and Stratmann, F.: Hygroscopic growth and activation of HULIS particles: experimental data and a new iterative parameterization scheme for complex aerosol particles, Atmos. Chem. Phys., 8, 1855-1866, 2008,

http://www.atmos-chem-phys.net/8/1855/2008/. 